\title{
Editorial
}

\section{Care free? The after effects of being a carer}

The importance of the care provided by family members, friends and neighbours to people who need special help due to disability or frailty is beyond question. The effects of caring on health, social and financial well-being have been well researched. ${ }^{1}$ But when caring ceases, problems may not end. Caring brings joys as well as difficulties $^{2}$; its cessation entails loss. Moreover, the financial and employment disadvantages associated with being a long-term carer continue after caring ceases. New research 3,4 contrasts the incomes, employment and pension histories of over 1000 Britons aged 55 to 69 years who had been carers in the past with those of 1500 people who had not been carers. Data came from the 1988 Survey of retirement and retirement plans 5 conducted by the Office of Population Censuses and Surveys.
Consistent with research on current carers, ${ }^{6}$ differences between past carers en masse and noncarers were small, allowing for age, gender and retirement status. But people who had cared for more than ten years had lower incomes, were more likely to receive means-tested social security benefits and had spent less time in occupational pension schemes than those whose caring had lasted for shorter periods. Starting to care early in life appears detrimental to employment prospects after caring ceases, although past carers do seem to attempt to catch up for lost employment experience.

In retirement, men who had cared for more than ten years had average personal incomes of f7 a week lower (1988 prices) than those who had cared for shorter periods (Figure 1); the gap for women was £11. Differences were larger

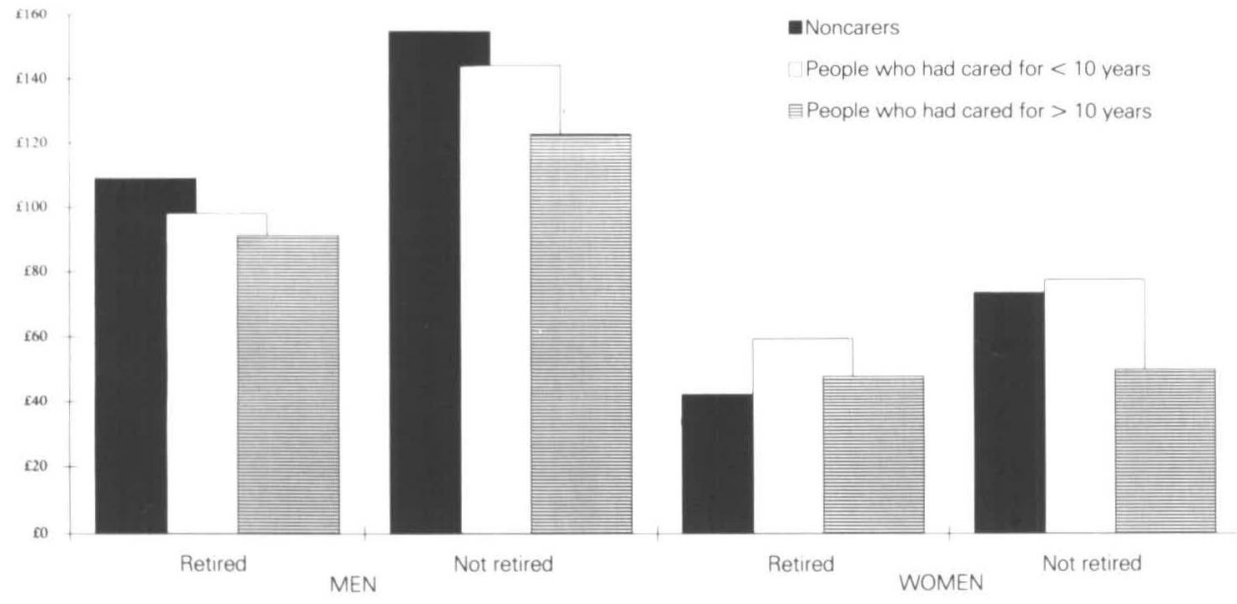

Figure 1 Average weekly personal income; by gender, carer and retirement status Source: Hancock R. Jarvis C. Tinker A, Askham J. ${ }^{4}$

C Edward Arnold 1995 


\section{Editorial}

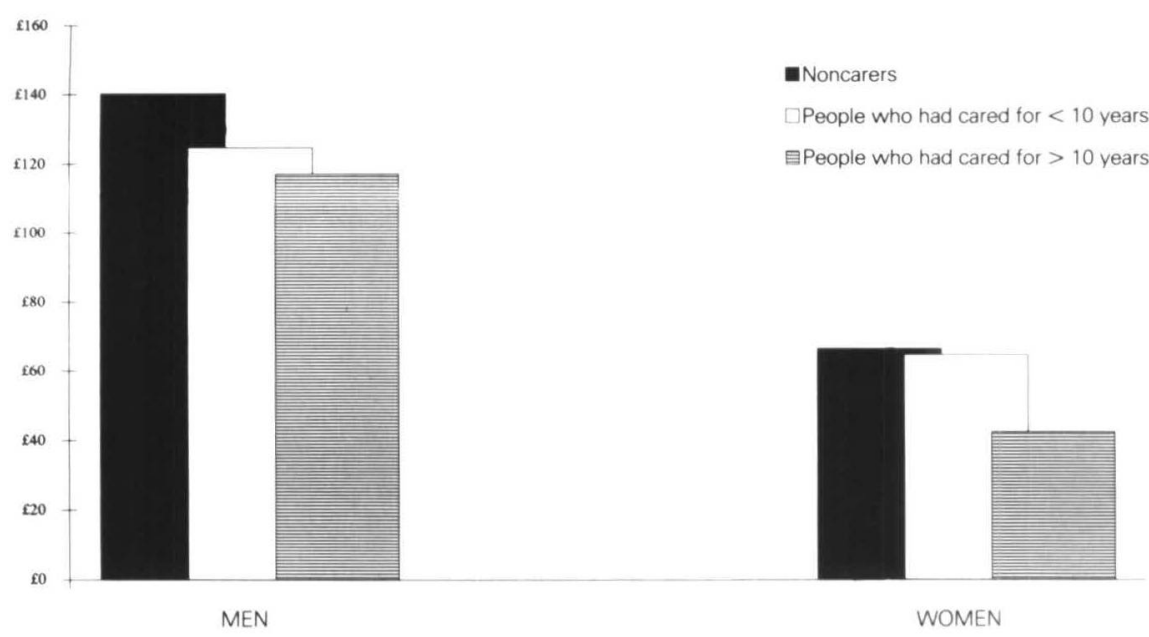

Figure 2 Average weekly income from employment, people working in the past week: by gender and carer status

Source: Hancock R, Jarvis C. Tinker A, Askham J.4

still for the nonretired, partly because long-term past carers had low earnings even when in work (Figure 2).

Differences between men and women, however, were greater than differences between past carers and noncarers, even taking account of the length of time spent caring. This may reflect what determines whether someone becomes a carer rather than the effects of caring. Even the worst-off group of male past carers, retired men who had cared for more than ten years, had average personal incomes which were $£ 14$ a week higher than the best-off group of women (nonretired who had cared for fewer than ten years).

Some findings are difficult to explain, for example past carers tended to have higher savings income than noncarers (perhaps due to inheritances). But the disadvantaged position of those who had cared for long periods stands out and confirms the importance of policies to protect their pension rights and employment opportunities.
Ruth Hancock and Claire Jarvis, Age Concern Institute of Gerontology, King's College London, UK.

\section{References}

1 Parker G. With due care and attention: a review of the literature on informal care. London: Family Policy Studies Centre, 1990.

2 Askham J, Grundy E, Tinker A. Caring: the importance of third age carers. The Carnegie inquiry into the third age, research paper number 6 . Dunfermline: Carnegie UK Trust, 1992.

3 Hancock R,'Jarvis C. The long term effects of being a carer. HMSO, 1994.

4 Hancock R, Jarvis C, Tinker A, Askham J. After care: summary findings from a study of the long-term effects of being a carer. London: HMSO, 1994.

5 Bone M, Gregory J, Gill B, Lader D. Retirement and retirement plans. London: HMSO, 1992.

6 Parker G, Lawton D. Different types of care, different types of carer: evidence from the General Household Survey. London: HMSO, 1994. 